$\mathbf{2 7}(1)$, 123-132

\title{
Asymmetric Effects of Inflation Uncertainty on Facilities Investment
}

\author{
Minkyu Son ${ }^{a} \cdot$ Youngjae Chang ${ }^{b, 1}$ \\ ${ }^{a}$ Research Department, The Bank of Korea \\ ${ }^{b}$ Department of Information Statistics, Korea National Open University
}

(Received November 19, 2013; Revised December 12, 2013; Accepted January 27, 2014)

\begin{abstract}
Inflation uncertainty is known to have deleterious effects on facilities investment by disturbing the corporate decision on the opportunity cost of investment. In this paper, we test the validity of this hypothesis in Korea by estimating the inflation uncertainty with both a time-varing parameter model with GARCH disturbances and the relative price volatility and then, estimate the facilities investment equation which includes those uncertainty indicators. The uncertainty indexes estimated by the above-mentioned methods continue to fluctuate even after the inflation rate has dropped dramatically reflecting the structural changes of Korea's economy since the financial crisis in 1997. As a result of estimation of the investment equation by both OLS and GMM, we find the inflation uncertainty has a negative effect on facilities investment with a statistical significance. Moreover, by means of Markov-switching regression model utilized to verify the non-linearity of this relationship, we draw a conclusion that this negative effect of inflation uncertainty heightens asymmetrically during the downturn periods of business cycle.
\end{abstract}

Keywords: Inflation uncertainty, facilities investment, Markov-switching regression model, time-varying GARCH model.

\section{1. 서론}

\section{1. 인플레이션 불확실성과 기업투자간 관계}

경제의 불확실성 (uncertainty) 증대가 기업 투자를 중심으로 한 거시경제 전반에 미치는 영향은 그간 다 수의 국내외 연구를 통해 다루어져 왔다. 대표적으로 Pindyck (1991), Dixit (1992) 등은 기업 투자의 비가역성(irreversibility)으로 인해 경제의 불확실성 증대가 기업들의 투자를 위축시킬 수 있다고 주장 하였다. 투자의 비가역성이란 기업이 계획된 투자를 일단 실행에 옮기면 의사결정에 오류가 있었음이 밝혀지더라도 투자 중단에 따른 손실, 즉 투입한 자본재를 싼 가격으로 되파는 데 따라 발생하는 손실 로 인해 투자를 철회하지 않는 경향이 있음을 의미한다. 특히 Pindyck (1991) 등은 투자가 비가역적일 경우 현재의 생산능력 확충은 미래에 설비과잉상황이 발생할 경우 상당한 투자감축비용을 지불할 위험 을 감수하는 것이기 때문에 기업이 투자결정시 불확실성에 더욱 민감하게 반응하게 되고 불확실성을 제

${ }^{1}$ Corresponding author: Assistant Professor, Department of Information Statistics, Korean National Open University, 86 Daehak-ro, Jongno-gu, Seoul 110-791, Korea. E-mail: yjchang@knou.ac.kr 
거할 수 있는 정보를 얻을 때까지 투자를 보류할 가능성이 있음을 지적하였다. 한편, Chang과 Chun (2000) 등은 이러한 경제의 불확실성 중 특히 인플레이션과 관련된 불확실성이 기업의 투자를 위축시키 는 경로는 크게 리스크프리미엄 경로와 상대가격 변동성 경로로 구분할 수 있다고 보았다. 우선 인플레 이션의 불확실성이 높아지면 리스크프리미엄이 증가하여 시장금리가 상승함으로써 기업의 투자가 위축 될 수 있다. 둘째, 인플레이션의 불확실성 증가는 미래 시점에서 자본재 가격과 여타 재화가격간 상대 가격체계를 교란시켜 투자결정과정에서 기회비용의 산출을 어렵게 함으로써 기업의 신규투자에 부정적 인 영향을 줄 수도 있다. 이러한 인플레이션 불확실성과 기업 투자간 관계를 실증분석한 국내연구로는 Hong와 Kim (1993), Hong (1995), Chang과 Chun (2000), Shin과 Koo (2003), Son과 Cho (2013) 등 을 들 수 있으며, 대부분의 연구에서 인플레이션율 변동성 및 상대가격 변동성 등으로 대표되는 인플레 이션 불확실성이 투자에 부정적인 효과를 미치는 것으로 나타났다.

\section{2. 본 연구의 특징}

본 연구에서는 우리나라의 인플레이션 불확실성이 기업의 설비투자에 미치는 영향에 대한 실증분석을 시도하고자 하며, 그간 다수의 선행연구와는 다음의 두가지 측면에서 차별된다. 첫째, 인플레이션 불 확실성의 측정과 관련하여 기존의 연구와 유사하게 Bollerslev (1986)의 GARCH모형을 활용하되, 우 리나라의 경우 1990 년 이후 금융부문의 자유화와 1997년 외환위기를 전후로 경제 전반에 구조적 변화 를 거치면서 주요 경제변수간 관계가 크게 달라졌을 가능성이 있음을 감안하여 $\mathrm{GARCH}$ 분산 시변모수

모형(Time-Varing Parameter Model with GARCH Disturbances)을 도입하였다. 선행연구 중 Hong (1995) 또한 우리나라의 인플레이션에 대해 자기회귀항(AR)으로만 구성된 시변모수 $\mathrm{ARCH}$ 모형 추정 을 시도한 바 있으나, 본고에서는 인플레이션 결정요인을 Caporale 등 (2010)를 참고하여 인플레이션 의 자기회귀항 이외 다양한 거시경제변수를 포함하여 이론적 정합성을 강화하고자 하였다. 둘째, 인플 레이션 불확실성 지표가 기업의 설비투자에 미치는 영향이 경기국면을 비롯한 경제상황에 따라 비대칭 적(asymmetry)일 가능성을 고려하여 설비투자 결정식을 기존의 선형모형 이외 마코프 국면전환 회귀 모형(Markov-Switching Regression Model)으로도 추정해보았다. 이는 불확실성이 기업의 투자심리와 연결됨에 따라 경기가 위축된 시기에 미래에 대한 불안 또는 비관적인 기대가 팽배한 상황에서 미래 경 제에 대한 불확실성이 설비투자에 미치는 효과가 더 커질 수 있다는 데 착안한 것이다.

\section{2. 인플레이션 불확실성 측정}

\subsection{GARCH분산 시변모수 모형(Time-Varing Parameter Model with GARCH Distur- bances) 추정}

본고에서는 여러 선행연구들을 참고하여 인플레이션과 관련한 불확실성을 인플레이션율 자체의 불확 실성과 품목별 상대가격 변동성으로 구분하여 살펴보았다. 인플레이션율의 불확실성을 산출하기 위해 Bollerslev (1986)의 GARCH(Generalized Autoregressive Conditional Heteroskedasticity) 모형을 활 용하였다. 그런데 전술한 바와 같이 우리나라의 경우 1990 년을 전후로 금융부문의 자유화 등 제도 변 화와 1997 년 외환위기를 전후로 경제 전반에 구조적 변화로 말미암아 각 시기별로 주요 경제변수들간의 관계가 크게 달라졌을 가능성이 있다. 이에 따라 본고에서는 Hong (1995), Caporale 등 (2010) 등의 논 의를 참고하여 인플레이션율 결정식을 시변모수모형(Time-Varying Model)으로 측정하고 동 결정식내 오차항의 분산이 GARCH과정을 따른다고 설정한 $\mathrm{GARCH}$ 분산 시변모수 모형(Time-Varing Parameter Model with GARCH Disturbances)을 활용하였다. 이러한 시변모수 모형을 통해 경제의 구조적 변화 등에 의해 유발된 경제주체들의 인플레이션 예측오차(forecast error)와 오차항의 GARCH변동성 
Table 2.1. Parameter estimates (standard error in parenthesis) for Time-Varying Parameter Model with GARCH Disturbances; $* * *, * *$ and $*$ represent significance at the level of $1 \%, 5 \%$ and $10 \%$

\begin{tabular}{cccccccc}
\hline$\sigma_{1}$ & $\sigma_{2}$ & $\sigma_{3}$ & $\sigma_{4}$ & $\sigma_{5}$ & $h$ & $a$ & $\lambda$ \\
\hline 0.064 & $0.045^{* *}$ & $0.005^{* *}$ & $0.003^{* *}$ & 0.000 & $0.034^{* *}$ & $0.309^{* *}$ & 0.313 \\
$(0.080)$ & $(0.011)$ & $(0.002)$ & $(0.001)$ & $(0.040)$ & $(0.084)$ & $(0.137)$ & $(0.224)$ \\
\hline
\end{tabular}

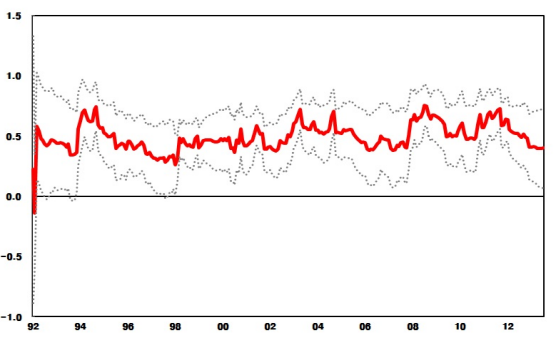

(a) Inflation Rate $(-1)$

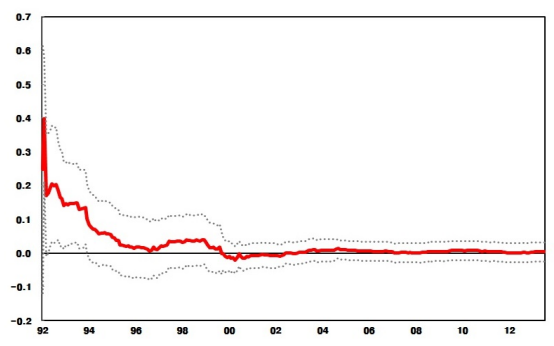

(c) Money Supply $(-1)$

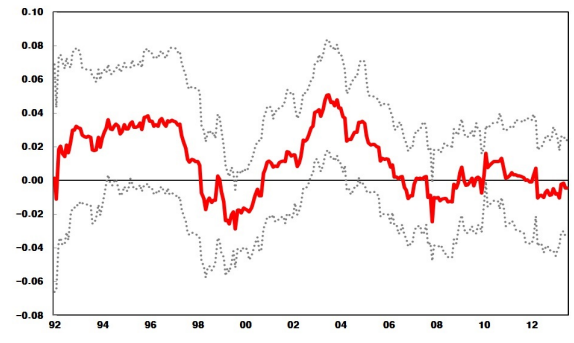

(b) Industrial Production $\operatorname{Index}(-1)$

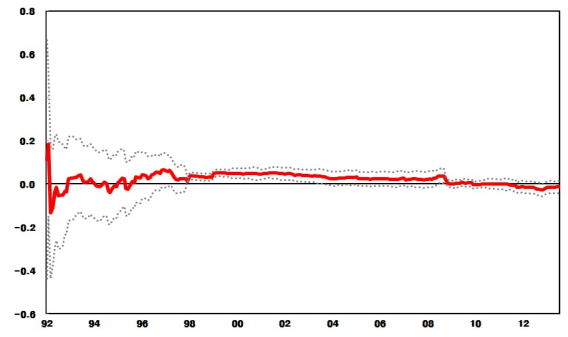

(d) Exchange Rate

Figure 2.1. Movement of the Estimated Time-Varying Parameters; Dotted lines indicate $90 \%$ confidence intervals.

을 합한 값을 총체적인 인플레이션율의 불확실성으로 간주하였다. GARCH모형을 통한 인플레이션 변 동성 측정시 인플레이션의 평균 방정식이 여타 설명변수를 고려하지 않고 주로 자기회귀과정을 따른다 고 단순화하는 것이 일반적이다. 이와 달리 본고에서는 자기회귀항 이외 인플레이션 결정요인으로 작용 할 수 있는 다양한 거시경제 변수들을 포함하여 평균방정식을 설정하고자 하며, 구체적인 설명변수로는 Caporale 등 (2010) 등을 참고하여 통화량(M2), 산업생산지수, 원달러환율을 포함하였다. 통화량과 산 업생산지수는 수요측 요인으로, 원달러환율은 주로 수입물가를 중심으로 한 공급측 요인으로 해석할 수 있다. 추정기간은 1990.1월부터 2013.7월로 하였으며, 모든 변수는 전년동기대비 증가율로 변환하였다. 원달러환율을 제외한 모든 변수는 1 기의 시차(lag)를 두었다.

동 시변모수 GARCH모형을 칼만필터(Kalman filter)를 활용한 최적화(optimization) 과정을 통 해 추정한 결과, 아래와 같은 평균방정식 (2.1)과 분산방정식 (2.2)를 얻었다. 여기서 $\pi_{t}$ 는 인플 레이션율, $X_{t}=$ (상수항, $\pi_{t-1}$, 통화량증가율 $(-1)$, 산업생산지수증가율 $(-1)$, 원달러환율상승률), $\epsilon_{t}$ 는 오차항, $h_{t}$ 는 $\mathrm{GARCH}$ 변동성을 의미한다. 또한, $\epsilon_{t} \sim N\left(0, h_{t}\right)$ 이며 $V_{t} \sim N(0, Q)$ 이고 $Q=$ $\operatorname{diag}\left(\sigma_{1}{ }^{2},{\sigma_{2}}^{2},{\sigma_{3}}^{2}, \sigma_{4}{ }^{2}, \sigma_{5}{ }^{2}\right)$ 로서 각 시변모수 오차항들로 이루어진 분산행렬이다.

동 모형 추정 결과 도출된 인플레이션 결정요인의 시변모수 $\left(\beta_{t}\right)$ 추이를 살펴보면 Figure 2.1과 같다. 앞 서 언급한 바와 같이 우리나라가 그간 경제의 구조적 변화와 각종 제도 변화를 거치면서 각 설명변수 


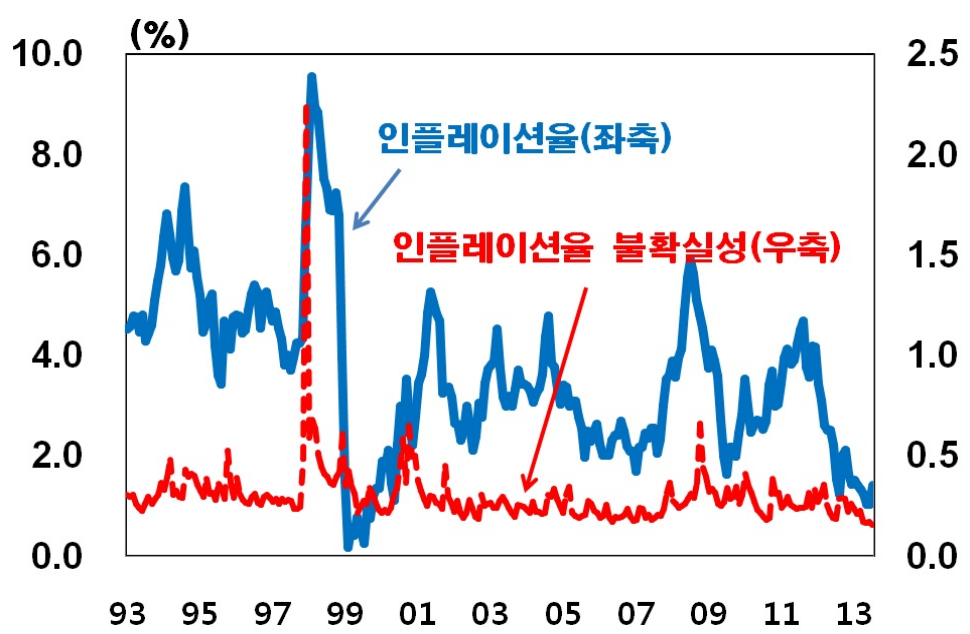

Figure 2.2. Inflation Rate(solid line, left axis) and Inflation Uncertainty(dotted line, right axis)

들의 인플레이션에 대한 영향력이 시간에 따라 크게 달라지는 양상을 보이고 있다. 구체적으로 인플레 이션의 시차항은 인플레이션 지속성(persistence)을 반영하여 높은 양 $(+)$ 의 영향력을 보이고 있는 반 면, 통화량증가율의 경우 1990 년대 이후 전세계적인 금융환경 및 제도 변화에 따른 통화수요의 불안정 성 등으로 인해 인플레이션에 대한 영향력이 크게 떨어진 모습이다. 총수요 내지 경기를 반영하는 산 업생산지수증가율은 대체로 인플레이션에 유의한 양 $(+)$ 의 영향력을 보이고 있으나 1997 년 외환위기 및 2008년 글로벌 금융위기 등 경기가 급속도로 침체된 시기에는 인플레이션에 대한 영향력의 부호가 달라 진 바 있다. 원달러환율은 수입비용 경로로서 그간 우리 경제의 대외개방도가 지속적으로 확대됨에 따 라 2000 년을 전후하여 인플레이션에 대해 대체로 유의한 양 $(+)$ 의 영향력을 보이고 있다.

$$
\begin{aligned}
\pi_{t} & =X_{t} \beta_{t}+\epsilon_{t}, \\
\beta_{t} & =\beta_{t-1}+V_{t}, \\
h_{t} & =h+a \epsilon_{t-1}^{2}+\lambda h_{t-1} .
\end{aligned}
$$

이러한 시변모수 추정을 통해 인플레이션 예측오차(forecast error)와 오차항의 GARCH변동성을 합하 여 인플레이션율 불확실성을 산출한 후 실제 인플레이션율과 추이를 비교해 보았는데, Figure 2.2 와 같 이 1998년 물가안정목표제를 채택한 이후 물가상승률이 구조적으로 낮아진 2000년 이후에도 변동성이 빈번하게 등락을 보이는 모습이다.

\section{2. 상대가격 변동성 추정}

한편, 인플레이션과 관련한 불확실성은 앞서 논의한 바와 같이 인플레이션율 자체의 불확실성 외에 개 별 품목별 상대가격의 변동성으로도 측정할 수 있다. 본고에서는 Shin과 Koo (2003), Kim과 Moon (1998) 등을 참고하여 상대가격 변동성을 일정시점에 우리나라 소비자물가지수내 포함된 전 품목의 평 균 가격상승률과 개별품목의 가격상승률간 분산으로 산출하였다. 이에 따라 품목별 상대가격의 변동 성(relative price volatility)은 식 (2.3)과 같이 정의되며, 동 변동성 지수를 산출하여 인플레이션과 추 이를 비교해보면 Figure 2.3 과 같다. 여기서 $\pi_{i t}$ 는 상품 $i$ 의 물가상승률, $\bar{\pi}_{t}$ 는 전품목 평균물가상승률을 


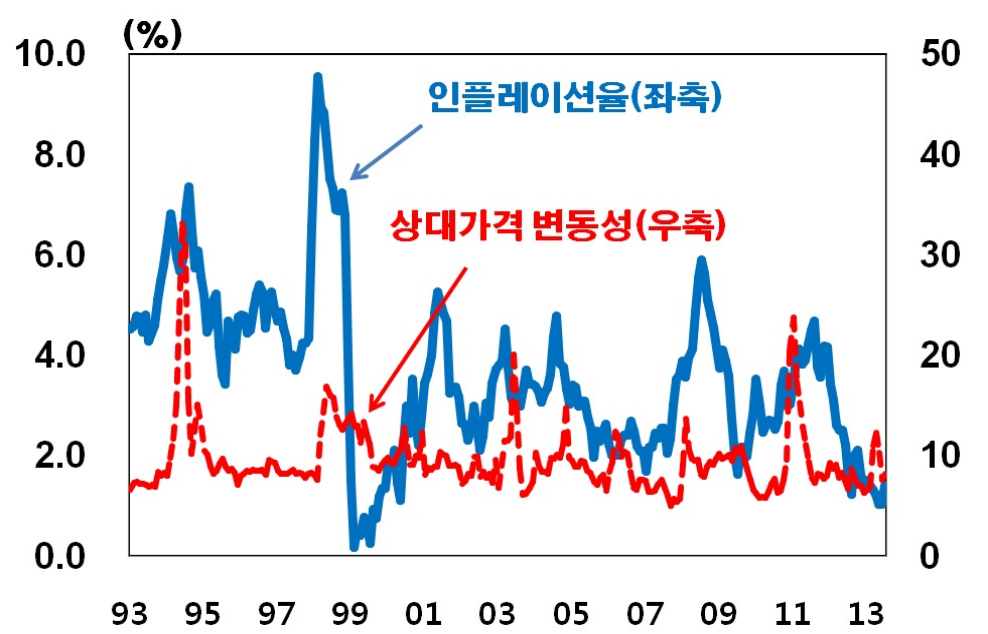

Figure 2.3. Inflation Rate(solid line, left axis) and Relative Price Volatility(dotted line, right axis)

의미한다.

$$
\operatorname{RPV}_{t}=\left[\sum_{i=1}^{n} w_{i t}\left(\pi_{i t}-\bar{\pi}_{t}\right)^{2}\right]^{0.5}, \quad t=1,2, \ldots, T
$$

추정 결과, Kim과 Moon (1998) 등 선행연구와 마찬가지로 상대가격 변동성이 인플레이션율과 전반 적으로 양의 상관성(상관계수: 0.36)을 보이고 있으며, 인플레이션율의 절대수준이 구조적으로 낮아진 2000 년 이후에도 $\mathrm{GARCH}$ 변동성의 경우처럼 상대가격 변동성이 빈번하게 등락을 거듭하는 것으로 나 타났다.

\section{3. 인플레이션 불확실성의 설비투자에 대한 영향}

\section{1. 선형모형}

이번 절에는 설비투자 결정모형을 식 (3.1)과 같이 설정하여 인플레이션 관련 불확실성과 설비투자간 관계를 명시적으로 점검해보았다. 동 모형에는 기존 국내외 연구를 참고하여 산업생산지수(수요요인), 원달러환율(비용 + 수요요인), 실질금리(비용요인)과 함께 인플레이션 관련 불확실성을 의미하는 인플 레이션율 불확실성 또는 상대가격 변동성을 추가하였다. 설명변수의 예상부호를 살펴보면 산업생산지 수는 수요요인으로서 설비투자에 정 $(+)$ 의 영향을, 원달러환율의 경우 수입자본재의 가격변동에 따른 음 $(-)$ 의 효과와 외화표시 수출가격 변동에 따른 양 $(+)$ 의 효과가 동시에 발생함에 따라 동 계수의 부호 는 두 요인의 상대적 크기에 따라 달라진다. 또한 실질금리는 비용요인으로서 부(-)의 영향을 미칠 것 으로 기대된다. 마지막으로 인플레이션 불확실성과 관련된 변수 또한 불확실성이 투자에 미치는 이론 이 우리나라에서도 성립한다면 부(-)의 영향을 미칠 것으로 예상된다. 한편, 모형내 양 $(+)$ 의 자기상 관(autocorrelation)을 완화하고자 시차종속변수를 추가하였으며, 원달러환율, 실질금리 등은 시차를 두 고 설비투자에 영향을 미친다고 보아 $1 \sim 2$ 기의 시차를 적용하였다. 산업생산지수는 시차값을 넣을 경우 여러 변수들의 추정 계수값의 부호가 이론과 많이 상이해지고 통계적 유의성도 떨어지는 것으로 나타났 다. 이에 따라 산업생산지수는 당기값을 포함하되, 이에 따라 야기될 수 있는 내생성(endogeneity) 문 
Table 3.1. Parameter estimates (standard error in parenthesis) for Determinants of Facilities Investment; $* * *, * *$ and $*$ represent significance at the level of $1 \%, 5 \%$ and $10 \%$ and [ ] represents $P$-value for $J$-Statistics.

\begin{tabular}{|c|c|c|c|c|}
\hline \multirow{2}{*}{$\begin{array}{c}\text { 추정기간 } \\
\text { (불확실성지표) }\end{array}$} & \multicolumn{2}{|c|}{ OLS } & \multicolumn{2}{|c|}{ GMM } \\
\hline & (GARCH변동성) & (상대가격 변동성) & (GARCH변동성) & (상대가격 변동성) \\
\hline \multirow{2}{*}{ 설비투자지수 $(-1)$} & $0.559^{* * *}$ & $0.563^{* * *}$ & $0.590^{* * *}$ & $0.622^{* * *}$ \\
\hline & $(0.036)$ & $(0.037)$ & $(0.033)$ & $(0.037)$ \\
\hline \multirow{2}{*}{ 산업생산지수 } & $0.797^{* * *}$ & $0.796^{* * *}$ & $0.825^{* * *}$ & $0.714^{* * *}$ \\
\hline & $(0.067)$ & $(0.070)$ & $(0.067)$ & $(0.078)$ \\
\hline \multirow{2}{*}{ 원달러환율 $(-1)$} & -0.048 & -0.061 & 0.002 & -0.052 \\
\hline & $(0.041)$ & $(0.041)$ & $(0.038)$ & $(0.034)$ \\
\hline \multirow{2}{*}{ 불확실성 $(-1)$} & $-10.277^{* * *}$ & $-0.327^{* * *}$ & $-12.526^{* * *}$ & $-0.307^{* * *}$ \\
\hline & $(1.766)$ & $(0.063)$ & $(1.732)$ & $(0.051)$ \\
\hline \multirow{2}{*}{ 회사채수익률 $(-2)$} & -0.106 & -0.105 & -0.217 & -0.045 \\
\hline & $(0.202)$ & $(0.207)$ & $(0.155)$ & $(0.148)$ \\
\hline $\operatorname{Adj} \cdot R^{2}$ & 0.905 & 0.902 & 0.906 & 0.903 \\
\hline D.W. & 2.118 & 2.053 & 2.203 & 2.242 \\
\hline \multirow{2}{*}{$J$-통계량 } & & & 24.402 & 23.474 \\
\hline & & & {$[0.496]$} & {$[0.550]$} \\
\hline
\end{tabular}

제를 점검하기 위해 일반화적률법 $(\mathrm{GMM})$ 을 통한 추정도 병행해 보았다. 일반화적률법을 적용하기 위 해서는 도구변수로서 설명변수의 $1 \sim 6$ 개월 전의 시차값을 이용하였다. 추정기간은 통계청의 설비투자 지수가 입수 가능한 1996.1월부터 2013.7월로 하였다.

$$
\Delta \operatorname{inv}_{t}=\beta_{0} \Delta \operatorname{inv}_{t-1}+\beta_{1} \Delta \operatorname{prod}_{t}+\beta_{2} \Delta \operatorname{exr}_{t-1}+\beta_{3} \Delta \operatorname{rate}_{t-2}+\beta_{4} \Delta u_{n c} c_{t-1}+u_{t} .
$$

식 (3.1)에서 $\operatorname{inv}_{t}$ 는 설비투자지수, $\operatorname{prod}_{t}$ 는 산업생산지수, $\operatorname{exr}_{t}$ 는 원달러환율, $\operatorname{rate}_{t}$ 는 3 년 만기 회사채 수익률(AA-), unc $t$ 는 인플레이션 불확실성 지표, $\Delta$ 는 전년동기대비 증감(율)을 의미하며 원달러환율 과 인플레이션 불확실성을 제외한 모든 변수는 소비자물가상승률로 실질화하였다.

추정 결과 원달러환율과 실질금리 등 전통적인 설비투자의 비용 관련 요인의 경우 대체로 해당 계수값 의 부호는 이론에 부합하나 통계적 유의성은 다소 낮은 것으로 나타났다. 특히 실질금리의 경우 Gong (1999), Choi (2004) 등도 우리나라 설비투자 변동에 미치는 영향이 미미하다는 결과를 제시한 바 있으 며, 이러한 점을 감안하여 Chang과 Chun (2000), Yoon (2004) 등을 비롯한 다수 연구에서는 실질금리 를 설비투자 결정식에서 제외하기도 하였다. 또한 환율의 경우 앞서 지적한 바와 같이 비용요인과 수요 요인이 혼재됨에 따라 계수값의 방향이 명확하지 않게 나타났다. 이와 달리 투자의 수요요인인 산업생 산지수와 인플레이션 불확실성 지표는 공히 높은 유의성을 보였다. 이는 우리나라의 설비투자 결정요인 이 앞서 소개한 선행연구들의 결과와 유사하게 경기요인과 함께 인플레이션에 내재된 경제의 불확실성 에 큰 영향을 받음을 시사한다. 마지막으로 GMM을 통한 추정결과가 OLS의 결과와 계수값의 방향 및 유의성, 모형의 설명력 측면에서 전반적으로 유사한 것으로 나타나 산업생산지수의 당기값을 포함한 데 따른 내생성 문제는 크지 않은 것으로 판단된다.

\section{2. 경기국면별 비대칭성 분석을 위한 비선형모형}

본 절에서는 앞서 살펴본 설비투자 결정요인이 경제상황에 따라 그 영향력이 상이한 지를 살펴보고 자 한다. 이를 위해 경제상황별 비대칭성을 분석하는 데 널리 이용되고 있는 마코프 국면전환 회귀모 


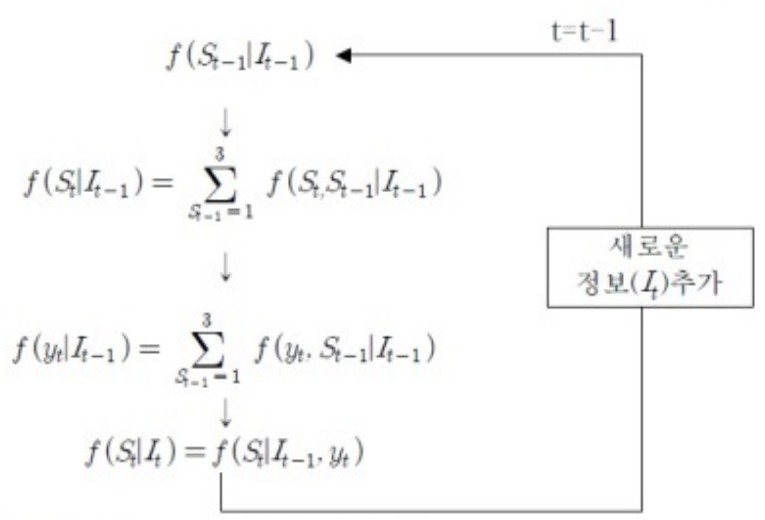

Figure 3.1. Hamilton-Filtering procedure

형(Markov-Switching Regression Model)을 이용하여 설비투자 결정식을 추정하고 각 국면별 설비투자 결정요인들의 계수값간 비교를 시도하였다. 이때 상이한 경제상황을 포착하고자 설정된 국면은 모형의 단순화를 위해 2 개로 설정하였다. 설비투자의 국면전환 회귀식은 식 (3.2)와 같고 마코프과정을 따르는 국면전환확률은 식 (3.3)과 같다. 각 식에서 $y_{t}$ 는 실질설비투자지수, $X_{t}=\left(y_{t-1}\right.$, 실질산업생산지수, 실질회사채수익률 $(-2)$, 원달러환율 $(-1)$, 인플레이션 불확실성 지표 $), \epsilon_{t}$ 는 평균 0 , 표준편차 $\sigma$ 인 정규 분포를 따르는 오차항, $S_{t}$ 는 국면(1 또는 2$)$ 을 의미한다. 인플레이션 불확실성을 제외한 모든 변수는 전 년동기대비 증감(율)을 사용하였으며 추정기간은 1996.1월 2013.7월로 하였다.

$$
\begin{aligned}
y_{t} & =X_{t}^{\prime} \beta_{S_{t}}+\epsilon_{t}, \\
p_{i j} & =P\left(S_{t}=j \mid S_{t-1}=i\right), \quad \sum_{j=1}^{2} p_{i j}=1, i=1,2 .
\end{aligned}
$$

$\mathrm{Oh}$ (2007)을 참고하여 마코프 국면전환 회귀모형 추정 절차를 설명하면 다음과 같다. 먼저 위의 식 (3.2)는 회귀계수 $\left(\beta_{S_{t}}\right)$ 및 오차항의 분산 $\left(\sigma_{S_{t}}^{2}\right)$ 이 개별 국면 $\left(S_{1}, S_{2}\right)$ 에 종속되도록 모형화한 것이다. 다 만 본고에서는 추정의 편의를 위해 조건부분산이 국면과 무관하게 동일하다고 보았다(즉, $\left.\sigma_{S_{t}}^{2}=\sigma^{2}\right)$. 또한 식 (3.3)은 국면을 나타내는 비관측변수인 $S_{t}$ 에 대한 전환확률(transition probability)로서 마코프 과정(Markov process)을 따른다고 보았다. $t-1$ 기의 국면과 $t$ 기의 국면이 각각 2 개씩이므로 모두 4 가 지의 전환확률 조합이 존재하게 되며 $p_{i j}$ 는 $t-1$ 기의 $i$ 국면상태가 $t$ 기에는 $j$ 국면상태로 전환될 확률을 의미한다. 비관측변수인 국면 $S_{t}$ 와 이에 대한 전환확률을 추정하기 위해서는 아래의 Figure 3.1 과 같이 Hamilton (1989)이 제시한 filtering 방식을 사용하였으며, 구체적으로 Figure 3.1의 filtering 과정에서 는 $S_{t}$ 의 우도함수가 매 시기의 정보 $\left(I_{t}\right)$ 에 대해 조건부 $\left(S_{t} \mid I_{t}\right)$ 로 산출되며, 동 과정이 반복·완료되면 전 체기간의 정보 $\left(I_{T}\right)$ 를 담은 $S_{T}\left(=S_{T} \mid I_{T}\right)$ 를 얻을 수 있다. 모형의 계수와 국면전환 시점 추정을 위해 최 우추정법(MLE)이 이용된다.

동 filtering 과정이 완료되면 대상기간에 대한 모든 정보 $\left(I_{t}\right)$ 를 이용하여 $S_{t}$ 의 우도함수 $\left(f\left(S_{t} \mid I_{T}\right)\right)$ 를 재 추정하면 더욱 효율적인 확률경로의 추정이 가능해지며 이같은 절차를 평탄화(smoothing) 과정이라 한 다. 본고에서는 $\operatorname{Kim}$ (1994)이 제시한 알고리듬을 활용하여 평활화 확률을 도출하였다. 마코프스위칭 회귀모형 추정 결과는 Table 3.2 와 같다. 동 결과를 살펴보면 동 모형이 식별한 제 1 국면과 제 2 국면별 로 인플레이션 관련 불확실성 지표의 영향력이 상이함을 알 수 있다. 구체적으로 인플레이션율 변동성 
Table 3.2. Parameter estimates (standard error in parenthesis) for Markov switching model; ***, ** and * represent significance at the level of $1 \%, 5 \%$ and $10 \%$.

\begin{tabular}{|c|c|c|c|c|}
\hline & \multicolumn{2}{|c|}{ GARCH변동성 } & \multicolumn{2}{|c|}{ 상대가격변동성 } \\
\hline & 제1국면 & 제2국면 & 제1국면 & 제2국면 \\
\hline \multirow{2}{*}{ 설비투자지수(-1) } & $0.389^{* * *}$ & $0.593^{* * *}$ & $0.396^{* * *}$ & $0.549^{* * *}$ \\
\hline & $(0.047)$ & $(0.225)$ & $(0.043)$ & $(0.166)$ \\
\hline \multirow{2}{*}{ 산업생산지수 } & $1.022^{* * *}$ & $0.660^{* * *}$ & $1.018^{* * *}$ & $0.580^{* * *}$ \\
\hline & $(0.105)$ & $(0.163)$ & $(0.070)$ & $(0.160)$ \\
\hline \multirow{2}{*}{ 원달러환율 $(-1)$} & -0.009 & -0.021 & -0.009 & -0.123 \\
\hline & $(0.116)$ & $(0.165)$ & $(0.027)$ & $(0.137)$ \\
\hline \multirow{2}{*}{ 불확실성 $(-1)$} & $-5.714^{* *}$ & $-26.683^{* *}$ & $-0.170^{* * *}$ & $-0.720^{* * *}$ \\
\hline & $(2.763)$ & $(10.586)$ & $(0.067)$ & $(0.218)$ \\
\hline \multirow{2}{*}{ 회사채수익률 $(-2)$} & 0.149 & -0.806 & 0.149 & -0.779 \\
\hline & $(0.396)$ & $(0.941)$ & $(0.238)$ & $(0.745)$ \\
\hline \multirow{2}{*}{$\log (\sigma)$} & \multirow{2}{*}{\multicolumn{2}{|c|}{$\begin{array}{l}1.680^{* * *} \\
(0.060)\end{array}$}} & \multirow{2}{*}{\multicolumn{2}{|c|}{$\begin{array}{l}1.697^{* * *} \\
(0.058)\end{array}$}} \\
\hline & & & & \\
\hline log-likelihood & \multicolumn{2}{|c|}{-661.110} & \multicolumn{2}{|c|}{-662.009} \\
\hline D.W. & \multicolumn{2}{|c|}{2.180} & \multicolumn{2}{|c|}{2.167} \\
\hline
\end{tabular}

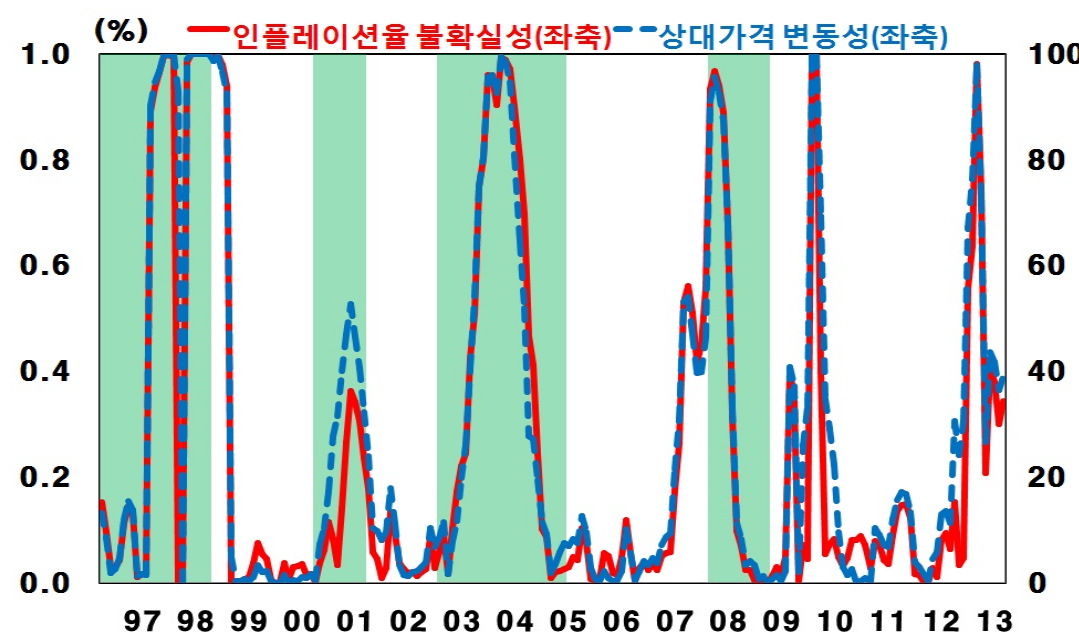

Figure 3.2. Solid Lines are the smoothed version of the 2nd Regime Probability from the Markov-Switching Regression Model. Shaded area indicates the contraction periods of the business cycle announced by Statistics Korea; Inflation Uncertainty(solid line, left axis) and relative price volitility(dotted line, left axis)

이 설비투자에 미치는 부정적인 영향이 제 2 국면에서 제 1 국면에 비해 약 5 배 확대되었다. 상대가격 변동 성도 마찬가지로 추정 계수값이 제 2 국면에서 제 1 국면에 비해 약 4 배 이상 증가하였다.

동 모형을 통해 추출된 제 2 국면 전환확률(Regime Probability)을 2009년까지 발표된 통계청의 경기수 축 국면과 비교해 본 결과, Figure 3.2 에서 알 수 있듯이 두 국면이 포함된 기간이 매우 유사한 것으로 나타나 제 1 국면이 경기확장기를, 제 2 국면이 경기수축기를 반영하였을 가능성이 매우 높다. 이는 경기 가 위축되는 시기에는 기업들의 투자 결정이 인플레이션 불확실성에 더 크게 반응함에 따라 인플레이션 불확실성이 특히 경기위축기에 기업의 설비투자를 위축시키는 중요한 요인이 될 수 있음을 시사한다. 


\section{4. 결론}

인플레이션의 불확실성은 리스크프리미엄 증가와 상대가격 교란 등을 통해 기업투자의 기회비용 산정 등에 어려움을 줌으로써 설비투자를 위축시키는 요인이 될 수 있다. 본고에서는 인플레이션 관련 불확 실성을 인플레이션율의 불확실성과 품목별 상대가격 변동성으로 각각 산출하여 추이를 살펴보았다. 산 출 결과, 우리나라의 인플레이션율이 구조적으로 낮아진 2000년대 이후에도 인플레이션 관련 변동성이 지속적으로 등락을 거듭하는 모습으로 보이고 있다. 다음으로 동 불확실성 지표들을 활용하여 설비투자 와의 관계를 점검한 결과, 인플레이션 불확실성은 예상한 바와 같이 기업의 설비투자에 유의한 부(-)의 영향을 야기하는 것으로 나타났다. 특히 이러한 인플레이션 불확실성의 비대칭적 효과를 살펴보기 위해 설비투자 결정식을 마코프 국면전환 회귀모형으로 추정한 결과, 인플레이션 불확실성의 계수값의 크기 가 경기위축기로 식별되는 국면(regime)에서 음(-)의 방향으로 크게 증가하는 것으로 나타났다. 이는 인플레이션의 불확실성이 경기위축기에 설비투자 위축을 심화시키는 중요한 요인으로 작용할 수 있음을 시사한다.

\section{References}

Bollerslev, T. (1986). Generalized autoregressive conditional Heteroskedasticity, Journal of Econometrics, 31, 307-327.

Caporale, G. M., Onorante, L. and Paesani, P. (2010). Inflation and Inflation Uncertainty in the Euro Area, ECB Working Paper, 1229.

Chang, K. and Chun, B. (2000). Analysis of the recent behavioral change of facilities investment, $B O K$ Monthly Bulletin, December 2000, Bank of Korea.

Choi, C. (2004). The effects of changes in exchange rate level and volatility on investment, Economic Analysis, 5, Bank of Korea.

Dixit, A. (1992). Investment and hysteresis, Journal of Economic Perspectives, 6, 107-132.

Gong, J. (1999). The effect of exchange rate volatility on Korea's facility investment, Journal of Social Science Research, 6, 459-475.

Hamilton, J. D. (1989). A new approach to the economic analysis of nonstationary time series and the business cycle, Econometrica, 57, 357-384.

Hong, S. (1995). Analysis of the determinants of facilities investment with stochastic trend and inflation uncertainty, Kukje Kyungje Yongu, 9 75-97.

Hong, S. and Kim, Y. (1993). Decomposition of inflation uncertainty and its effect on the real economy, Seoul Journal of Economics(in Korean), 32, 11-36.

Kim, C. and Moon, S. (1998). Inflation and relative price volatility, Economic Analysis, 4, Bank of Korea.

Kim, C. J. (1994). Dynamic linear models with Markov-Switching, Journal of Econometrics, 60, 1-22.

Oh, H. (2007). Structural break in potential growth and business cycle after Korean currency crisis, Journal of Money and Finance, 21, 19-53.

Pindyck, R. (1991). Irreversibility, uncertainty and investment, Journal of Economic Literature, 29, 11101148 .

Shin, S. and Koo, J. (2003). Inflation, inflation uncertainty and investment, Kukje Kyungje Yongu, 9, $207-223$.

Son, M. and Cho, H. (2013). The effect of inflation on corporate investment, BOK Monthly Bulletin, September 2013, Bank of Korea.

Yoon, S. (2004). Change in dynamic relationship between exchange rate and facilities investment, $B O K$ Monthly Bulletin, July 2004, Bank of Korea. 


\title{
인플레이션 불확실성의 기업 설비투자에 대한 비대칭적 효과 분석
}

\author{
손민규 $^{a}$. 장영재 ${ }^{b, 1}$ \\ ${ }^{a}$ 한국은행 조사국, ${ }^{b}$ 한국방송통신대학교 정보통계학과
}

(2013년 11월 19일 접수, 2013년 12월 12일 수정, 2014년 01월 27일 채택)

\section{요 약}

인플레이션의 불확실성은 기업투자의 기회비용 산정 등에 어려움을 줌으로써 설비투자를 위축시킬 수 있다. 본 연구 에서는 우리나라에서도 이러한 가설의 성립여부를 검정하고자 시변모수(Time-Varying) GARCH모형과 품목별 상 대가격 변동성을 통해 인플레이션과 관련된 불확실성을 측정하고 동 불확실성이 기업의 설비투자에 미치는 영향을 살펴보았다. 인플레이션 불확실성을 인플레이션율의 불확실성과 품목별 상대가격 변동성으로 각각 산출하여 추이를 살펴보면 우리나라의 인플레이션율이 구조적으로 낮아진 2000년대 이후에도 인플레이션 관련 변동성이 등락을 거듭 하는 모습으로 보이고 있다. 또한, 동 지표들을 활용하여 설비투자와의 관계를 점 검한 결과 인플레이션 불확실성은 예상한 바와 같이 기업의 설비투자에 유의한 부(-)의 영향을 미치는 것으로 나타났다. 특히 이러한 인플레이션 불 확실성의 비대칭적 효과를 살펴보기 위해 마코프 국면전환 회귀모형(Markov-Switching Regression Model)을 추 정한 결과, 인플레이션 불확실성의 투자위축 효과가 경기위축기에 더욱 커지는 것으로 나타났다.

주요용어: 인플레이션 불확실성, 설비투자, 마코프 국면전환 회귀모형, 시변모수 GARCH모형.

1교신저자: (110-791) 서울특별시 종로구 대학로 86 , 한국방송통신대학교 정보통계학과, 조교수.

E-mail: yjchang@knou.ac.kr 